\title{
SUPPORTING INVESTMENT FOR SUSTAINABLE URBAN DEVELOPMENT
}

DOI: http://dx.doi.org/10.18509/GBP.2020.82

UDC: 332.146.2:711.4]:330.322(4-672EU)

\author{
Andreea-Mariana Manta \\ Răzvan-Cătălin Dobrea \\ Virgil Profeanu \\ Mihaela Minciu \\ The Bucharest University of Economic Studies, Romania
}

\begin{abstract}
The purpose of the present paper is to explore a potential solution to promote the investment projects' development in order to obtain sustainable urban growth.

In the first part, the article highlights the considerable global importance of sustainable urban development. Moreover, it identifies examples of good practices related to implementation of instruments used for stimulating investments which are focused on achieving sustainable urban development.

In the succeeding part, the article describes the identified potential solution, respectively a process which can be applied in practice in any city in order to attain sustainable development.

The research was based on the specific scientific publications, the available official data related to sustainable urban development and on the experience of the authors in the studied domain.

The results of the research will contribute to drawing up a new methodology that will stimulate investments for improving the process of urban growth considering the principle of sustainable development.
\end{abstract}

Keywords: sustainability, development, investment, urban growth

\section{INTRODUCTION}

This article describes a possible solution to the current problems encountered in the urban environment related to a better management of the investments. Solving the current problems will empower sustainable development of the cities.

The main challenges of sustainable development are: the limited financial resources to develop sustainable development; sustainable development is very difficult to achieve in war - torn countries; unforeseen events such as: earthquakes and hurricanes often delay sustainable development as they destroy infrastructure; governmental decisions against sustainable development; corruption is another hurdle in the way of sustainable development as it causes financial losses and delays; lack of implication at regional and municipal level [1].

Most of these challenges can be unravelled by developing smart investments. As Luiz Alexandro Mejia mentions in his article entitled "Maximizing the impact of sustainable development investment", "Investing and financing are the first steps on the road to sustainability"[2]. 


\section{LITERATURE REVIEW}

The United Nations defined sustainable development in "Our Common Future" as: "development that meets the needs of the present without compromising the ability of future generations to meet their own needs" [3].

Sustainable development has multiple dimensions of which the most important are presented in the Figure 1:

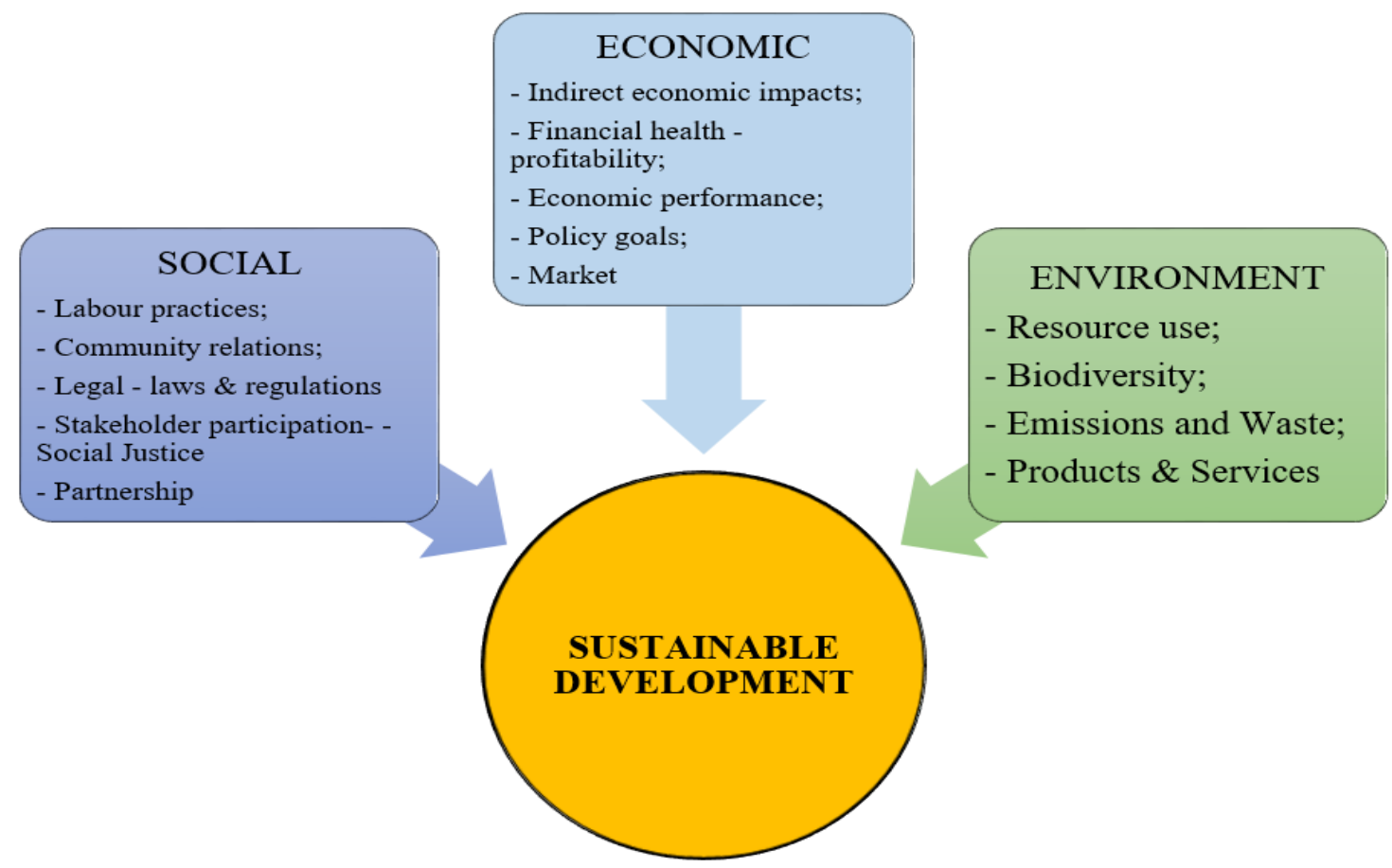

Figure 1. Dimensions of Sustainable Development Source: adapted from [4]

In 2015 The United Nations Member States approved the 2030 Agenda for Sustainable Development, which presents a global plan for unity and well-being for the entire planet, in the present and in the future. The Agenda proposes 17 Sustainable Development Goals to be reached until 2030 that should represent a priority for all types of countries, whether or not developed [5].

In the following Figure 2, these 17 goals are illustrated: 


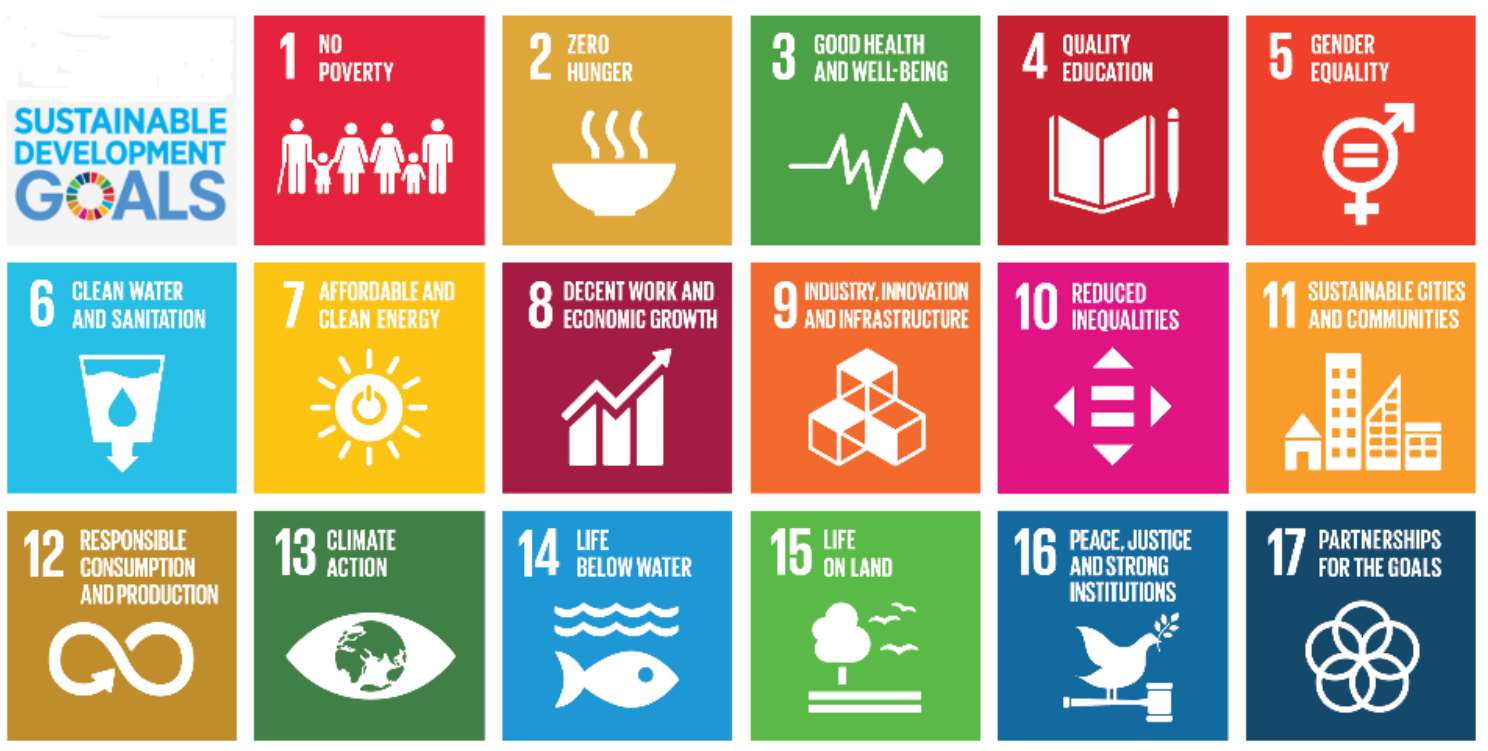

Figure 2. Sustainable Development Goals, Source: [5]

The $11^{\text {th }}$ Goal refers to sustainable cities and communities. In order to reach this goal, it is absolutely necessary that all people will have a reasonable shelter. Then, all should have access to transportation and basic services. Moreover, inclusive and sustainable urbanization is required. Protection of the cultural and natural heritage is another objective to reach this goal. Furthermore, it is imperious to reduce the number of deaths and people affected by disasters. Another objective is to reduce the harmful effects of the environmental impact of cities by improving air quality and waste management. Due to their numerous benefits, it is required to offer access to green and public spaces. Also, the connections between urban and rural areas should be encouraged from economic, social and environmental perspective using regional and national growth planning [6].

"The Sustainable Development Goals (SDGs) explicitly call for quality investment to support this transformation" [7].

A very important facilitator of human and economic development are private investments as they increase the number of jobs, encourage the local firms', suppliers and distributors through the market they create for their products and services. Investments enhance access to infrastructure and services. Along with the investments made by national firms, the international investments empower important benefits, such as: innovation, sustain productivity rise using new technologies and information. Moreover, the business linkages from different countries contribute to expertise and new technologies spread and create connection to global value chains and markets.

Investment can also improve people's skills through adequate training and educational projects so that the number of unemployed will decrease.

The power of investment to enable economic growth is highlighted by many examples. One example is represented by the investments in Southeast Asia that contributed to a record in performance of export [7].

The International Institute for Sustainable Development (IISD) underlines some of the latest improvements related to Sustainable Development. Therefore, it mentions about the initiatives to preserve government policy in order to defend the objectives related to environmental and social aspects. Another improvement is the relation between governmental measures for social, environmental safety and the scope of unbiased 
treatment standard under investment regulations. New rules imposed related to investors' responsibilities on compliance with local laws [8].

According to "Sustainable development in the European Union", 2019 edition, more than EUR 100 billion from the European funds was allocated for investments in cities between 2014 and 2020 to empower sustainable development of the cities. However, the situation related to sustainable development in the Member States is far from ideal. The following Table 1 presents relevant information extracted from this report [9]:

Table 1. Sustainable Development Goals in Europe SDG

Goal no. 1 - No poverty

Goal no. 2 - Zero Hunger

Goal no. 3 - Good health and well - being

Goal no. 4-Quality education

Goal no. 5 - Gender equality

Goal no. 6-Clean water and sanitation

Goal no. 7 - Affordable and clean energy Goal no. 8 - Decent work and economic growth

Goal no. 9 - Industry, innovation and infrastructure

Goal no. 10 -Reduced inequalities

Goal no. 11 -Sustainable cities and communities

Goal no. 12 - Responsible consumption and production

Goal no. 13 -Climate action

Goal no. 14 - Life below water

Goal no. 15 - Life on land

Goal no. 16 - Peace, justice and strong institutions

Goal no. 17 - Partnership for the goal
Numbers in 2017

85.3 million people at risk of income poverty

$15.2 \%$ of the adult population were obese

A child born could on average expect to live 80.9 years $95.4 \%$ of young children participated in early childhood education and care

The tertiary education attainment rate of women was $10.1 \%$ higher than for men in 2018

15 Member States reported that more than $80 \%$ of their population were connected to at least secondary wastewater treatment

$55.1 \%$ of the energy consumed was imported

$21.0 \%$ of GDP was invested in 2018

$2.06 \%$ of GDP was spent on R\&D

The income of the richest $20 \%$ of the households was 5.1 times higher than that of the poorest $20 \%$

$13.3 \%$ of the population lived in poor dwelling conditions

118.5 grams of $\mathrm{CO} 2$ per $\mathrm{km}$ were emitted by new passenger cars

The EU reduced its primary energy consumption by $5.8 \%$ between 2002 and 2017

$86.3 \%$ of coastal water bathing sites had excellent water quality in 2017

784252 square kilometres of land area was protected in 2018 under the Natura 2000 network

51 billion euros were spent by governments on law courts

155 billion EUR were spent on financing to developing countries

Source: adapted from [9]

In a European study entitled "The making of a smart city: best practices across Europe", successful examples in developing smart investments are presented.

One of the cities included in the study is Barcelona, which implemented the project "GrowSmarter". 10 refurbished buildings were included in the project with an overall gross floor area of $33.110 \mathrm{~m}^{2}$. After the implementation of the project the energy demand decreased by 2767 MWh every year [10].

Another city from the study is Bristol which implemented the "Replicate" project through which smart technology decreased the quantity of energy consumed, increased the use of local renewable sources of energy, empowered sustainable mobility, involved citizens in the use of energy and significantly reduced $\mathrm{CO}_{2}$ emissions [10]. 
Cities along with industrial and scientific organisations participated in a project entitled "InSMART" in order to discover solutions for the present and future city's energy needs. They succeeded in finding the appropriate measures to ensure a sustainable energy prospective taking into consideration economic, environmental and social aspects involved. The cities that has been tested in the project were: Evora, Cesena, Trikala and Nottingham [10].

"PLEEC" project's purpose was to connect scientific knowledge, innovation and determined cities to achieve reduced energy use in Europe and to contribute to 20-20-20 European targets. The six cities that took part in this project were Eskilstuna, Turku, Tartu, Santiago de Compostela, Jyväskylä and Stoke-on-Trent [10].

"STEEP" was a European project implemented in cooperation between Florence, Bristol and San Sebastian. The project adopted a common methodology and used open-data source to increase efficiency in the value chain. The cities took advantage of their expertise and knowledge related to smart city concepts in order to obtain sustainable development [10].

\section{RECOMMENDED SOLUTION}

Based on the successful examples presented, the authors propose a possible solution to empower sustainable urban development through investments in smart programmes and projects.

In the first place, the authorities should identify the common needs of all the cities from a region taking into consideration the economic, environmental and social aspects. Moreover, all the local stakeholders should be involved. Also, it is necessary to analyse the mobility needs and to understand the energy use in every sector.

Then the authorities should prioritise the needs identified by consulting the potential beneficiaries.

The following step is to propose possible projects to meet the needs, mentioning their goals, objectives, beneficiaries, implementing location. In this step similar projects should be consulted in order to verify if there are solutions available for some of the identified needs.

The next step is to estimate budgets for every project.

The authority requests the necessary funds, using Integrated Territorial Investment (ITI) which "will both provide flexibility for Member States regarding the design of Operational Programmes, and enable the efficient implementation of integrated actions through simplified financing" [11].

ITI enables every Member State to obtain funds from different priority axes of more Programmes in order to implement strategy in an integrated way for a particular territory or region [11].

The public financial management approves a certain percent of the total budget.

The most important projects will receive funding for implementation.

The entire process is illustrated in the Figure 3 below: 


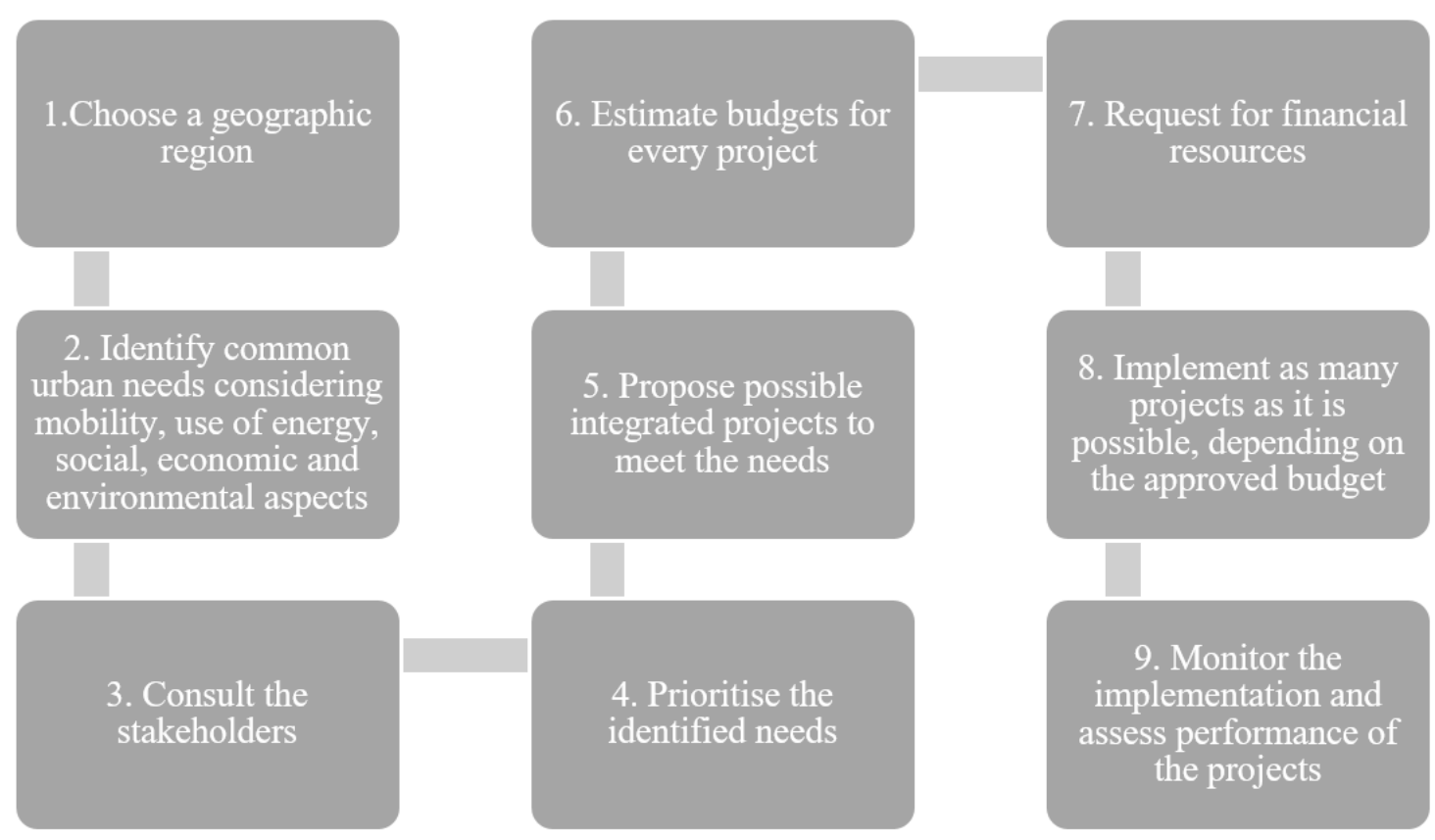

Figure 3. Process for urban sustainable development Source: own contribution

\section{RESEARCH METHODS}

In this article, the research method applied was the documentary analysis.

The documentary analysis was made on the available public official data related to sustainable development of cities, sustainable objectives imposed, smart projects for achieving sustainable growth.

\section{CONCLUSIONS}

The article proposes a process that can be applied in any region and city in order to obtain sustainable development. Taking into consideration the present studies related to social, environmental and economic dimensions in Europe, there is an urgent need to identify smart and innovative solutions to address the current urban problems.

Several countries have already invested in sustainable development and there are lots of good practices examples in implementing the necessary projects and since partnerships between countries are encouraged, the expertise and knowledge will be shared and adapted to the specific needs of every urban settlement.

\section{Acknowledgment}

This work was co-financed from the European Social Fund through Operational Programme Human Capital 2014 - 2020, project number POCU/380/6/13/125015 entitled "Development of entrepreneurial skills for doctoral students and postdoctoral researchers in the field of economic sciences".

\section{REFERENCES}

[1] Olga Adhikari - International Young Naturefriends, Sustainable Development and its Challenges in Developing Countries, 2018, Retrieved from: http://www.iynf.org/2018/08/aguide-to-sustainable-development-and-its-challenges-in-developing-countries/; 
[2] Luis Alejandro Mejía - Inter-American Development Bank, Maximizing the impact of sustainable development investment, 2019, Retrieved from: https://blogs.iadb.org/bidinvest/en/

[3] United Nations, Report of the World Commission on Environment and Development: Our Common Future, Retrieved from: https://sustainabledevelopment.un.org/content/documents/5987our-common-future.pdf

[4] P. Rana \& Mike Gregory \& Jim Platts, Exploration of corporate social responsibility (CSR) in multinational companies within the food industry, CORPORATE RESPONSIBILITY RESEARCH CONFERENCE 2008, Volume: 2, 2009, Retrieved from: https://www.researchgate.net/publication/237457674_Exploration_of_corporate _social_responsibility_CSR_in_multinational_companies_within_the_food_industry [5] United Nations, Sustainable Development Goals, 2015, Retrieved from: https://sustainabledevelopment.un.org/sdgs

[6] United Nations, Transforming Our World: The 2030 Agenda For Sustainable Development, A/RES/70/1, pp 24, 2015, Retrieved from: https://sustainabledevelopment.un.org/content/documents/21252030\%20Agenda\%20for $\% 20$ Sustainable\%20Development\%20web.pdf

[7] OECD, Investment for Sustainable Development, OECD AND POST - 2015 Reflections, Element 11, Paper 3, Retrieved from: https://www.oecd.org/dac/Post\%202015\%20Investment\%20for\%20sustainable\%20deve lopment.pdf

[8] IISD, Investment Policy Best Practices Advisory Bulletins, Retrieved from: https://iisd.org/project/investment-policy-best-practices-advisory-bulletins

[9] Eurostat, Sustainable development in the European Union Monitoring report on progress towards the SDGs in an EU context, Luxembourg: Publications Office of the European Union, 2019, Retrieved from: https://ec.europa.eu/eurostat/documents/3217494/9940483/KS-0219-165-EN-N.pdf/1965d8f5-4532-49f9-98ca-5334b0652820

[10] European Commission, The making of a smart city: best practices across Europe, GOPA Com, Printed in Belgium, 2017, Retrieved from: https://smartcitiesinfosystem.eu/sites/default/files/document/the_making_of_a_smart_city__best_practices_across_europe.pdf

[11] European Commission, Integrated Territorial Investment - Cohesion Policy 2014-2020, March 2014, doi:10.2776/56347, Retrieved from: https://ec.europa.eu/regional_policy/sources/docgener/informat/2014/iti_en.pdf 